\title{
Prenatal diagnosis from maternal blood: simultaneous immunophenotyping and FISH of fetal nucleated erythrocytes isolated by negative magnetic cell sorting
}

\author{
Yun-ling Zheng, Nigel P Carter, Cathy M Price, Susan M Colman, Peter J Milton, \\ Gerald A Hackett, Melvyn F Greaves, Malcolm A Ferguson-Smith
}

\begin{abstract}
Fetal nucleated cells in the maternal circulation constitute a potential source of cells for the non-invasive prenatal diagnosis of fetal genetic abnormalities. We have investigated the use of the Magnetic Activated Cell Sorter (MACS) for enriching fetal nucleated erythrocytes. Mouse monoclonal antibodies specific for CD45 and CD32 were used to deplete leucocytes from maternal blood using MACS sorting, thus enriching for fetal nucleated erythrocytes which do not express either of these antigens. However, significant maternal contamination was present even after MACS enrichment preventing the accurate analysis of fetal cells by interphase fluorescence in situ hybridisation (FISH). To overcome this problem, we used simultaneous immunophenotyping of cells with the mouse antifetal haemoglobin antibody, UCH $\gamma$, combined with FISH analysis using chromosome $X$ and $Y$ specific DNA probes. This approach enables selective FISH analysis of fetal cells within an excess of maternal cells. Furthermore, we have confirmed the potential of the method for clinical practice by a pilot prospective study of fetal sex in women referred for amniocentesis between 13 and 17 weeks of gestation.

(f Med Genet 1993;30:1051-6)
\end{abstract}

There have been a number of reports showing the presence of nucleated cells of fetal origin in the maternal circulation during pregnancy. $\mathrm{Al}-$ though these cells are rare, they have generated great interest as a potential source of fetal cells for the non-invasive prenatal diagnosis of genetic abnormalities. Various fetal cell types (trophoblasts, erythrocytes, and leucocytes) cross the placenta and circulate within maternal blood. ${ }^{12}$ The cell type which appears to offer the most potential for prenatal diagnosis is the fetal nucleated erythrocyte as fetal lymphocytes may persist from previous pregnancies and syncytiotrophoblast may not reflect the fetal genome. Fetal nucleated erythrocytes have been isolated from maternal blood during pregnancy using monoclonal antibodies and flow sorting ${ }^{3-8}$ and have been detected as early as 11 weeks of gestational age. ${ }^{367}$

Analysis of fetal nucleated erythrocytes sorted from maternal blood generally has been restricted to the determination of fetal sex by use of the polymerase chain reaction (PCR) with Y specific primers. More recently, fluorescence in situ hybridisation (FISH) has been used for the detection of aneuploidies in flow sorted fetal cells. ${ }^{358}$ Trisomy 21 was found in this way in blood samples taken from pregnant women either after or, in one case, before chorionic villus sampling (CVS). However, the main problem with this approach is that the majority of the nucleated cells analysed are of maternal origin even after FACS sorting. Therefore, the diagnosis of fetal aneuploidy, which relies on the detection of abnormal numbers of hybridisation signals, is insensitive in these samples owing to the high level of normal maternal cell contamination and the inability to distinguish fetal cells from maternal cells.

We have investigated the use of the Magnetic Activated Cell Sorter (MACS) for enriching fetal nucleated erythrocytes. Leucocyte common antigen, CD45, is present on the cell surface of all mature human leucocytes and CD32 is present on mature granulocytes. Neither of these antigens appears to be expressed on nucleated erythrocytes. We have used mouse monoclonal antibodies to these antigens and MACS sorting to enrich fetal nucleated erythrocytes from maternal leucocytes by negative selection. The isolated cells have then been analysed by using fluorescence immunophenotyping with an antibody specific for fetal haemoglobin (Hb F) simultaneously with FISH. In this way, fetal cells are identified by the presence of $\mathrm{Hb} F$ and sexed using $\mathrm{X}$ and $\mathrm{Y}$ specific probes hybridised to these nuclei. The ability to focus the diagnostic procedure exclusively on cells of fetal origin represents a substantial advance on previous techniques.

\section{Materials and methods}

BLOOD SAMPLES AND CELL PREPARATION

Peripheral blood $(20 \mathrm{ml})$ was drawn into heparinised tubes from pregnant women before amniocentesis at between 13 and 17 weeks of gestational age. The blood was diluted 1:2 in phosphate buffered saline (PBS). Step gradients were prepared by pipetting $5 \mathrm{ml}$ of a mixture of Histopaque-1119 and Histopaque-1077 (Sigma, Poole, UK) in the ratio of 3:1 (density of approximately 1109) into a $50 \mathrm{ml}$ centrifugation tube and overlayering
Received 12 July 1993. Accepted 13 September 1993. 
with $5 \mathrm{ml}$ of Histopaque-1077. The diluted blood was overlayered onto the Histopaque1077 and then spun at $800 \mathrm{~g}$ for 30 minutes at room temperature. Cells at the plasma/Histopaque-1077 and Histopaque-1077/Histopaque-1109 interfaces and the complete Histopaque-1077 layer were removed into a fresh tube and washed once with PBS, once with PBS/ BSA/azide $(0.1 \%$ bovine serum albumin, $0.01 \%$ sodium azide in PBS), and then resuspended in $\mathrm{PBS} / \mathrm{BSA} /$ azide at $10^{6}$ cells per $100 \mu \mathrm{l}$. The cells were sorted within four to six hours of peripheral blood sampling. Newborn umbilical cord blood samples (obtained from the delivery unit at Rosie Maternity Hospital) and blood samples from normal male and female adults were prepared similarly and used to develop the methods and to act as controls.

\section{ANTIBODY STAINING PROCEDURES}

Isolated cells were incubated on ice for 25 minutes with $10 \mu \mathrm{l} / 10^{6}$ cells of mouse IgG2a anti-CD45 (Serotec Ltd, Kidlington, UK) and $2 \mu \mathrm{l} / 10^{6}$ cells of mouse IgG2a anti-CD32 (Serotec Ltd). The cells were washed in PBS/BSA/ azide twice, resuspended at $10^{7}$ cells per $80 \mu \mathrm{l}$ of PBS/BSA/azide, and incubated at 6 to $12^{\circ} \mathrm{C}$ for 15 minutes with $20 \mu \mathrm{l} / 10^{7}$ cells of magnetic microbeads conjugated to rat antimouse IgG2a antibody (Miltenyi Biotec $\mathrm{GmbH}$ ). The stained cells were washed with PBS/BSA/ azide once, resuspended in $2 \mathrm{ml}$ of $\mathrm{PBS} / \mathrm{BSA} /$ azide, and then immediately separated by MACS.

\section{MAGNETIC CELL SORTING}

Cells were separated by MACS (Miltenyi Biotec $\mathrm{GmbH}$ ) using columns of type A1 or A2 according to the binding capacity of the column, as recommended by the manufacturer. The flow through the separation column is regulated by the gauge $(G)$ of a disposable needle used at the outlet. Before use, columns were filled with $70 \%$ ethanol by injection from the bottom, washed with PBS/BSA $(0.5 \%$ BSA in PBS), incubated at room temperature with PBS/BSA for 15 to 30 minutes to saturate non-specific binding sites, and then flushed with ice cold PBS/BSA/azide. The labelled cells were applied to the top of the column placed within the permanent magnet of the MACS separator (Miltenyi Biotec $\mathrm{GmbH}$ ) and negative cells eluted by washing with three column volumes of PBS/BSA/azide at a flow speed of approximately $1.5 \mathrm{ml} / \mathrm{min}$ (22G needle). To increase the absolute recovery of negative cells, retained cells were processed a second time at a higher flow rate. The column was removed from the MACS separator and the bound cells flushed to the top of the steelwool matrix by injection of PBS/BSA/ azide from the bottom. The column was replaced into the MACS separator and the cells passed through the column at a flow speed of approximately $3.5 \mathrm{ml} / \mathrm{min}$ (21G needle). The column was washed with 5 to 10 column volumes of PBS/BSA/azide and the two fractions of eluted cells pooled.

\section{SLIDE PREPARATION AND IMMUNO-} PHENOTYPING

Mouse IgG1 antifetal haemoglobin antibody $(\mathrm{UCH} \gamma),{ }^{9}$ which binds specifically to fetal erythrocytes, was used to immunophenotype the isolated cells. The specificity of the $\mathrm{UCH} \gamma$ was tested on direct smears of cord blood and normal adult blood diluted 1 to 4 in PBS.

Preparations for microscopy were made using a cytocentrifuge (Shandon Southern, Runcorn, UK) from the cells isolated by MACS from maternal blood and from control samples. Cells from cord blood were used as positive controls and maternal cells before MACS separation were used as negative controls. The slides were air dried overnight, fixed in $2 \%$ formaldehyde in PBS at room temperature for 10 minutes, rinsed in Tris buffered saline (TBS) for two minutes twice, and washed in a TBS bath at room temperature for 10 minutes with magnetic stirring.

The staining procedures are modified from the method described by Cordell et $a l^{10}$ and Price et al. ${ }^{11}$ Slides were incubated in $10 \%$ normal goat serum (Sigma) in TBS at room temperature for 15 minutes and $30 \mu \mathrm{l}$ of $\mathrm{UCH} \gamma$ culture supernatant, diluted 1:80 in TBS containing $10 \%$ normal goat serum, was added to each slide and incubated at room temperature for 60 minutes in a humidified chamber. After washing the slides in TBS as before, $30 \mu \mathrm{l}$ of goat antimouse IgG1 alkaline phosphatase (Euro-Path Ltd, Bude, UK) diluted 1:60 was added to each slide and incubated at room temperature for 60 minutes in a humidified chamber (the antibody was diluted in TBS with $10 \%$ normal rat serum, incubated on ice for 30 minutes, and spun for 10 minutes in a microcentrifuge before use). The slides were then washed as above and two to three drops of alkaline phosphatase Vector Red substrate (Vector, Bretton, UK) were added to each slide. Colour development was monitored using a light microscope. Finally, the slides were washed in a TBS bath for 15 minutes, counterstained with haematoxylin, air dried, mounted in an aqueous mounting medium (Glycerol Gel, DAKO Ltd, High Wycombe, UK), and examined by light microscopy.

\section{FLUORESCENCE IN SITU HYBRIDISATION AND} DETECTION

After microscopic examination of the immunocytochemical staining, the coverslips were rinsed off by incubating in $2 \times \mathrm{SSC} / \mathrm{T}$ ween-20 $(0.05 \%$ Tween-20 in $2 \times \mathrm{SSC}, 1 \times \mathrm{SSC}=$ $0.15 \mathrm{~mol} / 1$ sodium chloride and $0.15 \mathrm{~mol} / \mathrm{l}$ sodium citrate, $\mathrm{pH} 7 \cdot 0$ ) at $50^{\circ} \mathrm{C}$ for 10 minutes and then the slides were washed in $2 \times \mathrm{SSC} /$ Tween -20 at $50^{\circ} \mathrm{C}$ for 15 minutes twice and dehydrated in ethanol series $(70 \%, 70 \%, 90 \%$, $90 \%$ ). The immunophenotyped cells were first probed with GMGY10, a chromosome Y specific repeat probe, ${ }^{12}$ and, if negative, reprobed with DXZ1, a chromosome $\mathrm{X}$ centromeric repeat probe. ${ }^{1314}$ Hybridisation of the cells was carried out as described previously ${ }^{15}$ with the exception that cells and probe were denatured together for 10 minutes at $90^{\circ} \mathrm{C}$. After 
hybridisation overnight at $42^{\circ} \mathrm{C}$, the coverslips were removed by rinsing in $2 \times$ SSC and the slides were washed twice in $50 \%$ formamide/ $1 \times \mathrm{SSC}$ at $45^{\circ} \mathrm{C}$ for five minutes, washed once in $1 \times \mathrm{SSC}$ at $45^{\circ} \mathrm{C}$ for five minutes, and once in $0.5 \times \mathrm{SSC}$ at $45^{\circ} \mathrm{C}$ for five minutes. The slides were then treated with alternating layers of fluoresceinated avidin DCS (Vector) and biotinylated goat anti-avidin (Vector), both at $5 \mu \mathrm{g} / \mathrm{ml}$ concentration in $4 \times \mathrm{SSC}, 0.05 \%$ Tween-20 $(4 \times \mathrm{T})$ containing $10 \%$ human $\mathrm{AB}$ serum, for 30 minutes at $37^{\circ} \mathrm{C}$ until two layers of avidin were applied. After each incubation in avidin or anti-avidin, the slides were washed three times at $45^{\circ} \mathrm{C}$ in $4 \times \mathrm{T}$ for five minutes. After the last wash in $4 \times \mathrm{T}$, the slides were rinsed in $2 \times \mathrm{SSC}$, and then mounted in $2.0 \mu \mathrm{g} /$ $\mathrm{ml}$ DAPI in Citifluor AFl antifade (Citifluor Ltd, London, UK).

\section{MICROSCOPY AND SIGNAL ANALYSIS}

To evaluate the enrichment of the MACS sorting, artificial mixtures of antibody stained (positive) and unstained (negative) lymphocytes were used. Antibody labelled cells were fluorescence labelled by replacing the magnetic microsphere layer of the standard protocol with successive layers of biotinylated horse antimouse IgG $\left(5 \mu \mathrm{l}\right.$ of $1.5 \mathrm{mg} / \mathrm{ml}$ per $10^{6}$ cells, Vector), fluorescein isothiocyanate conjugated streptavidin $\left(4 \mu \mathrm{l}\right.$ of $1 \mathrm{mg} / \mathrm{ml}$ per $10^{6}$ cells, Vector), and biotinylated magnetic microbeads $\left(5 \mu \mathrm{l}\right.$ per $10^{8}$ cells, Becton Dickinson, Oxford, UK). The slides were coded and the number of fluorescence negative and positive cells counted using an epifluorescence microscope both before and after MACS sorting.

In addition, slides of cells from umbilical cord blood prepared before and after MACS sorting were stained using Rapi-Diff II (HD Supplies, Aylesbury, UK) and the total number of nucleated erythrocytes present counted.

Immunophenotyped cells after MACS sorting of maternal blood were scored using an ordinary light microscope with a $20 \times$ objective. The position of $\mathrm{UCH} \gamma$ positive nucleated cells was recorded using a New England Finder (Graticules Ltd, Tonbridge, UK) and photographed. After FISH, the UCH $\gamma$ positive cells were relocated and analysed using a confocal laser scanning microscope (MRC600, Bio-Rad Microscience Ltd, Hemel Hempstead, UK). Analysis was carried out without knowledge of the fetal karyotype.

\section{Results}

The efficiency of the enrichment of rare cells by MACS was evaluated by using artificial mixtures of antibody stained and unstained cells (table 1). At the lowest tested frequency of one negative cell to 16.7 positive cells, MACS produced a purified negative fraction containing 11 negative cells to each positive cell. This represents an enrichment factor of 184.

The mouse anti-Hb F antibody, $\mathrm{UCH} \gamma$, was used to detect fetal erythrocytes by immunocytochemical staining. Almost $100 \%$ of nucleated erythrocytes and mature red cells in newborn cord blood smears were stained with this antibody (figure A). We did not find any positive nucleated cells on the direct blood smear slides of three non-pregnant women (approximately $1 / 4$ of the slide from each sample was scanned comprising at least $5 \times 10^{3}$ nucleated cells). However, in slides of Histopaque prepared cells from these three nonpregnant females, we found a small number of $\mathrm{UCH} \gamma$ positive nucleated cells $(1.4$ to 3 cells per million nucleated cells, 10 million cells scanned for each sample).

The efficiency of the hybridisation with GMGY10 and DXZ1 probes on immunostained cells was tested on cord blood and normal blood cells. The hybridisation efficiency in $\mathrm{UCH} \gamma$ negative cells was higher than in $\mathrm{UCH} \gamma$ stained positive cells (table 2). For example, hybridisation with GMGY10 showed single $\mathrm{Y}$ signals in $87 \%$ of $\mathrm{UCH} \gamma$ positive male cells (figure B) but $98 \%$ of $\mathrm{UCH} \gamma$ negative male cells.

The simultaneous immunophenotyping/ FISH analysis was applied to MACS processed peripheral blood samples from six pregnant women in a pilot prospective study. Three blood samples from non-pregnant adult females were used as negative controls. After gradient centrifugation, between 30 and $50 \times 10^{6}$ cells were isolated from the mononuclear cell layer from $20 \mathrm{ml}$ of blood. After MACS sorting, between 3 and $6 \times 10^{5}$ nucleated cells were collected from the magnetic negative fraction. $\mathrm{UCH} \gamma$ positive nucleated cells were detected in five out of six pregnant blood samples (table 3 , figure $\mathrm{C}, \mathrm{E}$ ) and no $\mathrm{UCH} \gamma$ positive nucleated cells were detected in the three non-pregnant blood samples. In the samples from the pregnant women, FISH with GMGY10 and DXZ1 showed four male pregnancies and one female pregnancy (figure $\mathrm{D}, \mathrm{F})$. Fetal sex determined in this way was in exact agreement with the cytogenetic analysis of amniotic fluid samples (table 3).

\section{Discussion}

It has been shown by others that fetal nucleated erythrocytes can be isolated from maternal blood by FACS sorting using anti-transferrin receptor and anti-glycophorin-A antibodies. ${ }^{3-8}$ However, this procedure is time consuming

Table 1 The efficiency of MACS separation using various ratios of labelled ( $+v e)$ and unlabelled (-ve) cells.

\begin{tabular}{|c|c|c|c|c|c|c|}
\hline \multicolumn{3}{|c|}{ Before MACS sorting } & \multicolumn{3}{|c|}{ After MACS sorting } & \multirow[b]{2}{*}{ Enrichment (fold) } \\
\hline No of - ve/ + ve cells & (Ratio) & Total No of - ve cells & No of $-\mathrm{ve}+\mathrm{ve}$ cells & (Ratio) & Total No of - ve cells & \\
\hline $\begin{array}{r}300 / 305 \\
100 / 675 \\
39 / 651\end{array}$ & $\begin{array}{l}(1: 1) \\
(1: 7) \\
(1: 17)\end{array}$ & $\begin{array}{l}1.0 \times 10^{6} \\
3.3 \times 10^{5} \\
2.0 \times 10^{5}\end{array}$ & $\begin{array}{l}632 / 36 \\
618 / 72 \\
627 / 57\end{array}$ & $\begin{array}{r}(18: 1) \\
(9: 1) \\
(11: 1)\end{array}$ & $\begin{array}{l}7.2 \times 10^{5} \\
2.7 \times 10^{5} \\
1.8 \times 10^{5}\end{array}$ & $\begin{array}{r}18 \\
58 \\
184\end{array}$ \\
\hline
\end{tabular}


and the equipment is expensive. We have investigated the use of negative selection by MACS sorting to enrich fetal nucleated erythrocytes from maternal blood. MACS sorting is a fast and inexpensive method compared to FACS and we have found that $20 \mathrm{ml}$ of prepared blood can be sorted in 10 minutes. The quality of MACS sorting depends not only on the immunomagnetic reaction, but also on the elution speed and volume. In this study, we used a minimal antibody concentration with a high sorting speed and large washing volumes to increase the absolute recovery rate of nucleated erythrocytes. Unfortunately, this strategy generates a high level of maternal nucleated cell contamination.

To date, there have been few reports of aneuploidy analysis by FISH of fetal cells from the maternal blood. ${ }^{358}$ Fetal cells circulating in maternal blood are rare and, as described above, the majority of nucleated cells sorted are of maternal origin. This is true even after FACS sorting. ${ }^{23568}$ The identification of fetal aneuploidy by interphase FISH relies on the detection of abnormal numbers of hybridisation signals in cell nuclei. Diagnosis using these sorted samples is inevitably insensitive and unreliable owing to the high level of
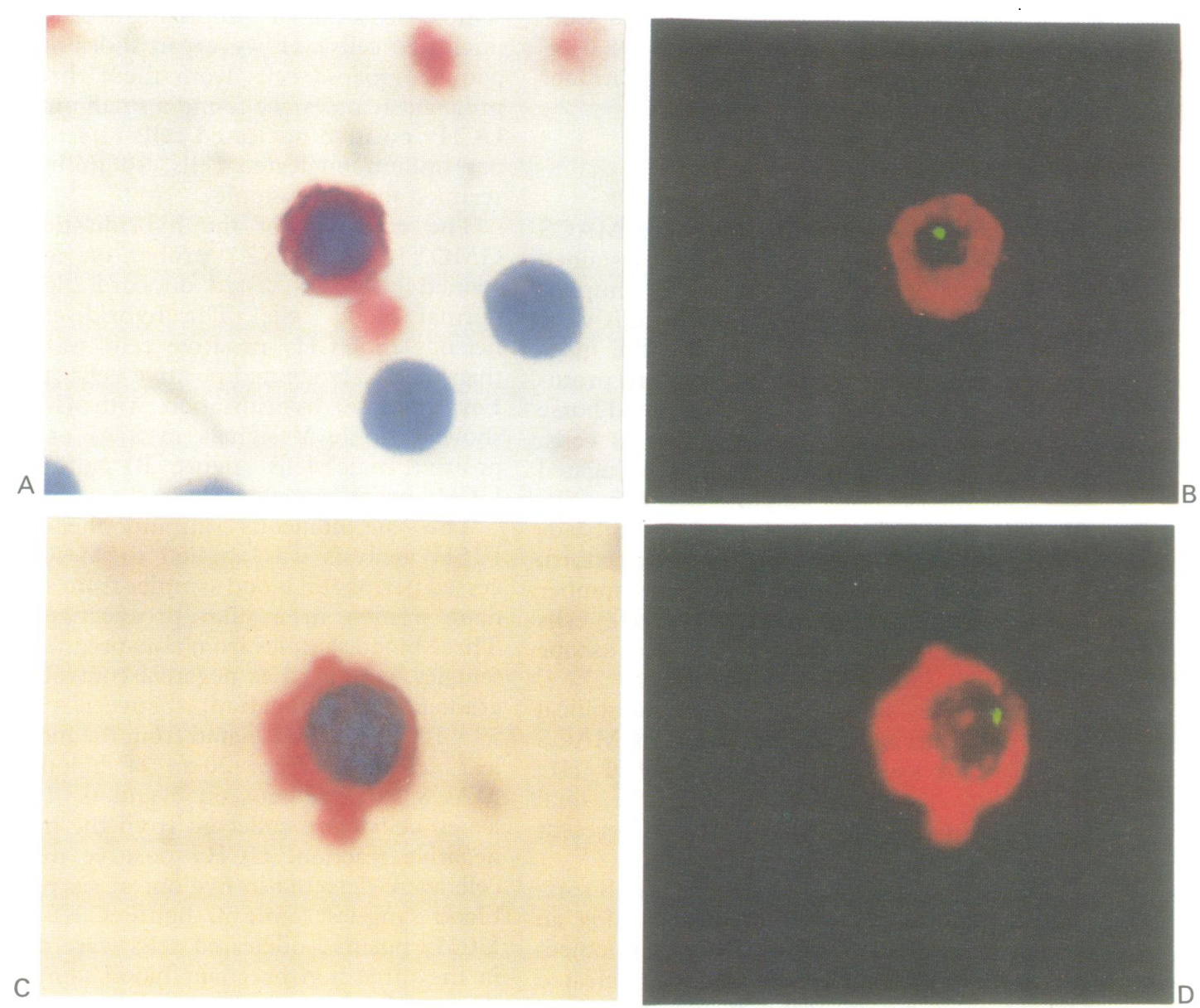

Micrographs. (A) Histopaque prepared new born cord blood cell smear showing a nucleated erythrocyte positive for $H b F$ by alkaline
phosphatase-Vector Red $(A P-V R)$ staining. $(B) A$ confocal image of a male nucleated erythrocyte from cord blood after anti-Hb $F / A P-V R$ phosphatase-Vector Red (AP-VR) staining. (B) A confocal image of a male nucleated erythrocyte from cord blood after anti-Hb F/AP-VR
staining (red fluorescence) and FISH with GMG Y10 probe (green fluorescence). (C) An anti-Hb F stained positive cell isolated from one of the maternal blood samples. (D) A confocal image of the same cell as in (C) after FISH with GMG Y10 probe showing a male genotype with one Y signal. (E) An anti-Hb F stained positive cell isolated from a second maternal blood sample. $(F) A$ confocal image of the same cell as in ( $E$ ) after FISH with DXZ1 probe showing a female genotype with two $X$ signals. 
Table 2 Hybridisation signal distribution in $\mathrm{UCH}_{\gamma}$ positive and negative immunostained cells.

\begin{tabular}{|c|c|c|c|c|c|c|c|}
\hline \multirow{3}{*}{$\begin{array}{l}\mathrm{UCH} \gamma \\
\text { staining }\end{array}$} & \multicolumn{7}{|c|}{ No of cells (\%) } \\
\hline & \multicolumn{3}{|c|}{ GMGY10 (male cells) } & \multicolumn{4}{|c|}{ DXZ1 (female cells) } \\
\hline & 0 & 1 & 2 & 0 & 1 & 2 & 3 \\
\hline Positive & $\begin{array}{c}37 \\
(12 \cdot 4)\end{array}$ & $\begin{array}{c}259 \\
(86.9)\end{array}$ & $\begin{array}{c}2 \\
(0 \cdot 6)\end{array}$ & $\begin{array}{c}60 \\
(12 \cdot 6)\end{array}$ & $\begin{array}{c}91 \\
(19 \cdot 1)\end{array}$ & $\begin{array}{c}325 \\
(68 \cdot 3)\end{array}$ & $\begin{array}{c}0 \\
(0)\end{array}$ \\
\hline Negative & $\begin{array}{c}7 \\
(1 \cdot 5)\end{array}$ & $\begin{array}{c}457 \\
(97 \cdot 7)\end{array}$ & $\begin{array}{c}4 \\
(0 \cdot 9)\end{array}$ & $\begin{array}{c}16 \\
(3 \cdot 4)\end{array}$ & $\begin{array}{c}34 \\
(7 \cdot 3)\end{array}$ & $\begin{array}{c}415 \\
(88 \cdot 5)\end{array}$ & $\begin{array}{c}4 \\
(0.9)\end{array}$ \\
\hline
\end{tabular}

maternal cell contamination and the inability to distinguish fetal from maternal cells. We have shown in this study that the combination of immunophenotyping with mouse monoclonal anti-HbF antibody and FISH analysis allows the identification of fetal nucleated red blood cells within the excess of maternal cells and enables chromosome copy number to be determined for fetal cells alone. This combination of staining technologies represents a substantial advance on previous FISH analyses of fetal cells sorted from maternal blood.

The combination of FISH and immunophenotyping has been used by others for the simultaneous analysis of phenotype and genotype in both mitotic and interphase cells. ${ }^{111617}$ Price et $a l^{11}$ exploited the observation that the alkaline phosphatase-Fast Red reaction produces a bright red fluorescence that is visible by epifluorescence microscopy using both fluorescein and rhodamine filters. Fast Red immunofluorescence and FITC FISH signals can be visualised simultaneously in the same cell. We used a mouse monoclonal anti-fetal haemoglobin antibody (UCH $\gamma)$, which specifically binds to fetal erythrocytes, to immunophenotype the MACS processed cells. We used Vector Red as a substrate as it produces red fluorescence similar to but brighter than Fast Red.

Interestingly, we observed that $\mathrm{UCH} \gamma$ also binds to a small number of nucleated cells ( $1 \cdot 4$ to 3 cells per million nucleated cells) in Histopaque prepared cells from three non-pregnant women. We also noted that these $\mathrm{UCH} \gamma$ positive nucleated cells were morphologically similar to lymphocytes rather than to nucleated erythrocytes. After MACS sorting, we were unable to find these $\mathrm{UCH} \gamma$ positive cells in the magnetic negative fraction sorted from the same three blood samples. The lineage of these cells is unknown but they represent a potential problem for the analysis of true fetal cells isolated from maternal blood and identified using UCH $\gamma$. Indeed, in the male pregnancy of case 11 , one $\mathrm{UCH} \gamma$ positive cell obtained by
MACS enrichment showed two copies of the $\mathrm{X}$ chromosome and no $\mathrm{Y}$ signal (table 3), which suggests that this cell was of maternal origin. This one maternal $\mathrm{UCH} \gamma$ positive cell did not affect the determination of fetal sex as the majority of the other $\mathrm{UCH} \gamma$ positive cells showed Y hybridisation signals. It is clear that the precise nature and origin of these $\mathrm{UCH} \gamma$ positive maternal cells should be studied further.

In four other samples from pregnant women, fetal sex determined by $\mathrm{X}$ and $\mathrm{Y}$ probe hybridisation in the $\mathrm{UCH} \gamma$ positive nucleated cells obtained by MACS enrichment was also in exact agreement with fetal sex determined by fetal chromosome analysis (table 3 , figure). In the remaining one case studied, no $\mathrm{UCH} \gamma$ positive cells were detected. Possible explanations for the lack of $\mathrm{UCH} \gamma$ positive cells in this case include failure of the isolation process or the absence of fetal cells from the maternal blood. It is possible that $\mathrm{ABO}$ blood group differences between the mother and fetus could result in the rapid clearance of fetal cells from the maternal circulation. ${ }^{18}$

Currently, FISH used with interphase nuclei is not reliable for the diagnosis of all trisomies. ${ }^{1921}$ Problems of this technique include non-specific signals and incomplete hybridisation. It is also possible for signals to overlap in the two dimensional image of the three dimensional nucleus giving the incorrect number of signals. In other studies, the expected number of domains determined by interphase analysis with chromosome specific repeat probes varied between $67 \%$ and $98 \%$ of cells counted. ${ }^{22-24}$ Clearly, the hybridisation efficiency is a major factor influencing the accuracy of the diagnosis. However, it has been shown that for autosome aneuploidy analysis, a signal distribution of greater than $40 \%$ of cells showing the expected number of signals is required to give a reliable diagnosis of trisomy. ${ }^{22}$

In this study, hybridisation with $\mathrm{DXZ1}$ and GMGY10 probes in $\mathrm{UCH} \gamma$ positive cells showed the expected number of signals in $68 \%$ and $87 \%$ of cells counted, respectively. As the fetal cells isolated from $20 \mathrm{ml}$ of maternal blood are so few (table 3 ), the probability of incorrect diagnosis owing to inefficient hybridisation is of concern. If we assume that more than $50 \%$ of cells must show the expected number of signals to generate a correct diagnosis, we can calculate the probability of an incorrect diagnosis using the binomial distribution. ${ }^{25}$ Where we have only four cells to analyse with DXZ1 which produces two signals in $68 \%$ of $\mathrm{UCH} \gamma$ positive normal female

Table 3 Details of six blood samples from pregnant women studied by MACS/UCH $\gamma$ staining/FISH.

\begin{tabular}{|c|c|c|c|c|c|c|c|c|c|}
\hline \multirow[b]{2}{*}{ Case } & \multirow{2}{*}{$\begin{array}{l}\text { No of HbF + cells after } \\
\text { MACS sorting }\end{array}$} & \multicolumn{2}{|c|}{ FISH Y10 signals } & \multicolumn{3}{|c|}{ FISH DXZ1 signals } & \multirow[b]{2}{*}{ Gestation (weeks) } & \multirow[b]{2}{*}{ Sex by MACS/FISH } & \multirow[b]{2}{*}{ Karyotype by CAAF* } \\
\hline & & 0 & 1 & 0 & 1 & 2 & & & \\
\hline 8 & 2 & 0 & 2 & \multicolumn{3}{|c|}{ Not done } & 14 & $M$ & $46, X Y$ \\
\hline 9 & 3 & 3 & 0 & 0 & 1 & 2 & 17 & $\mathrm{~F}$ & $46, \mathrm{XX}$ \\
\hline $10+$ & 11 & 3 & 8 & 3 & 0 & 0 & 13 & $\mathbf{M}$ & $46, X Y$ \\
\hline $11_{+}^{+}$ & 6 & 2 & 3 & 0 & 1 & 1 & 13 & $M$ & $46, \mathrm{XY}$ \\
\hline $12^{+}$ & 3 & 0 & 3 & \multirow{2}{*}{\multicolumn{3}{|c|}{$\begin{array}{l}\text { Not done } \\
\text { Not done }\end{array}$}} & 13 & M & $46, X Y$ \\
\hline 13 & 0 & \multicolumn{2}{|c|}{ Not done } & & & & 13 & Failed & $46, X Y$ \\
\hline
\end{tabular}

* CAAF $=$ cytogenetic analysis of amniotic fluid.

† Three $\mathrm{Hb} F$ positive cells, which were both $\mathrm{Y}$ and $\mathrm{X}$ hybridisation negative, were in the middle of a cell clump and overlapped by other cells. † One of the Hb F positive cells was covered by other cells and could not be analysed by FISH. 
fetal cells (table 2), the probability of a misdiagnosis $(0,1$, or 2 cells showing the expected number of signals) is 0.36 . However, if the hybridisation efficiency is $95 \%$, the probability of incorrect diagnosis with four cells is greatly reduced $(p=0.01)$. If 10 cells are available for analysis by a probe with a hybridisation efficiency of $95 \%$, the probability of incorrect diagnosis is very low $\left(\mathrm{p}=6 \times 10^{-5}\right)$. Therefore, only a slightly more efficient MACS sorting technique, an increased volume of maternal blood, or more efficiently hybridising probes are needed for reliable routine diagnosis using the methods presented in this paper.

In conclusion, the MACS is a faster, less expensive technique than the FACS and allows a large volume of blood to be separated in a short period of time. While at present few fetal cells are recovered and maternal cell contamination is too great by both methods to allow accurate direct analysis by FISH, immunophenotyping with antibodies specific to cells of fetal origin enables selective FISH analysis of fetal cells within the excess of maternal cells. An important feature of this approach is that diagnostic results are available within three days after peripheral blood sampling. The application of multicolour FISH to these immunophenotyped cells would allow the visualisation of several probes simultaneously ${ }^{2627}$ and provide the potential for the detection of the common fetal aneuploidies directly from maternal peripheral blood samples. The methods presented in this paper represent a substantial advance on previous techniques used for analysis of fetal cells isolated from maternal blood and show that non-invasive prenatal diagnosis from maternal blood has the potential to become a practical routine procedure.

The authors are grateful to Ms G Aston and Mrs S Bishop and the other members of the Department of Ultrasound, Rosie Maternity Hospital for organising and supplying the maternal blood samples, Mrs M E FergusonSmith and the staff of the East Anglian Regional Cytogenetics Service for cytogenetic analysis of amniotic fluid samples, Professor P Beverley for the $\mathrm{UCH} \gamma$ hybridoma cell line, and Dr B Sun for useful discussions. This study was supported by grants from the Medical Research Council (NPC and MAF-S) and Kay Kendall Leukaemia Fund (CMP and MFG), and scholarships from the Cambridge Overseas Trust and from the Overseas Research Students Awards Scheme (YLZ).

1 Schröder J. Transplacental passage of blood cells. $\mathcal{f}$ Med Genet 1975;12:230-42.

2 Adinolfi $M$. On a non-invasive approach to prenatal diagnosis based on the detection of fetal nucleated cells in maternal blood samples. Prenat Diagn 1991;11:799-804.

3 Price JO, Elias S, Wachtel SS, et al. Prenatal diagnosis with fetal cells isolated from maternal blood by multiparameter flow cytometry. Am $\mathcal{F}$ Obstet Gynecol 1991;165:1731-7.

4 Wachtel S, Elias S, Price J, et al. Fetal cells in the maternal circulation: isolation by multiparameter flow cytometry and confirmation by polymerase chain reaction. Hum Reprod 1991;6:1466-9

5 Elias S, Price J, Dockter M, Wachtel S, Tharapel A, Simpson JL. First trimester prenatal diagnosis of trisomy 21 in fetal cells from maternal blood. Lancet 1992;340:1033.

6 Bianchi DW, Flint AF, Pizzimenti MF, Knoll JHM, Lat SA. Isolation of fetal DNA from nucleated erythrocytes in maternal blood. Proc Natl Acad Sci USA 1990;87:3279-83.

7 Bianchi DW, Stewart JE, Garber MF, Lucotte G, Flint AF. Possible effect of gestational age on the detection of fetal nucleated erythrocytes in maternal blood. Prenat Diagn 1991;11:523-8.

Diagn 1991;11:523-8.
8 Bianchi DW, Mahr A, Zickwolf GK, Houseal TW, Flint AF, Klinger KW. Detection of fetal cells with 47, XY, $\mathrm{AF}, \mathrm{K}$ linger KW. Detection of fetal cells with $47, \mathrm{XY}$,
+21 karyotype in maternal peripheral blood. Hum Genet +21 karyotype in

9 Allen C, Weereratne H, Gale R, Beverley PCL, Huehns ER. The use of monoclonal antibodies $\mathrm{UCH} \beta$ and $\mathrm{UCH} \gamma$ for the antenatal diagnosis of $\beta$-thalassaemia. $\mathrm{Br} \mathcal{f} \mathrm{Hae}-$ matol 1987;65:199-203.

10 Cordell JL, Falini B, Erber WN, et al. Immunoenzymatic labelling of monoclonal antibodies using immune complexes of alkaline phosphatase and monoclonal anti-alkaline phosphatase (APAAP complexes). $\mathcal{F}$ Histochem Cytochem 1984;32:219-29.

11 Price CM, Kanfer EJ, Colman SM, Westwood N, Barrett AJ, Greaves MF. Simultaneous genotypic and immunophenotypic analysis of interphase cells using dual-color fluorescence: a demonstration of lineage involvement in polycythemia vera. Blood 1992;80:1033-8.

12 Affara NA, Florentin L, Morrison N, et al. Regional assignment of $\mathrm{Y}$ linked DNA probes by deletion mapping assignment of Y linked DNA probes by deletion mapping and their homology with X-chromosome and auto

13 Yang TP, Hansen SK, Oishi KK, Ryder OA, Hamkalo BA. Characterization of a cloned repetitive DNA sequence concentrated on the human $\mathrm{X}$ chromosome. Proc Nat Acad Sci USA 1982;79:6593-7.

14 Willard HF, Smith KD, Sutherland J. Isolation and characterization of a major tandem repeat family from the human X chromosome. Nucleic Acids Res 1983;11:201733.

15 Zheng YL, Ferguson-Smith MA, Warner JP, FergusonSmith ME, Sargent CA, Carter NP. Analysis of chromosome 21 copy number in uncultured amniocytes by fluorescence in situ hybridization nat Diagn 1992;12:931-43.

16 Kibbelaar RE, van Kamp H, Dreef EJ, et al. Combined immunophenotyping and DNA in situ hybridization to study lineage involvement in patients with myelodysplasstudy lineage involvement in patients
tic syndromes. Blood 1992;79:1823-8.

17 Weber-Matthiesen K, Winkemann M, Müller-Hermelink A, Schlegelberger B, Grote W. Simultaneous fluorescence immunophenotyping and interphase cytogenetics: contribution to the characterization of tumor cells. $\mathscr{f}$ Histochem Cytochem 1992;40:171-5.

18 Clayton EM, Feldhaus WD, Whitacre FE. Fetal erythrocytes in the maternal circulation of pregnant women Obstet Gynecol 1964;23:915-19.

19 Verma RS, Luke S. Variations in alphoid DNA sequences escape detection of aneuploidy at interphase by FISH technique. Genomics 1992;14:113-16.

20 Lebo RV, Flandermeyer RR, Diukman R, Lynch ED, Lepercq JA, Golbus MS. Prenatal diagnosis with repetitive in situ hybridization probes. Am $\mathrm{f}$ Med Genet 1992;43:848-54.

21 Weier HUG, Gray JW. A degenerate alpha-satellite probe, detecting a centromeric deletion on chromosome-21 in an apparently normal human male, shows limitations of the Anal Cell Pathol 1992;4:81-6.

22 Klinger K, Landes G, Shook D, et al. Rapid detection of chromosome aneuploidies in uncultured amniocytes by using fluorescence in situ hybridization. Am f Hum Gene 1992;51:55-65.

23 Cremer T, Landegent J, Bruckner A, et al. Detection of chromosome aberrations in the human interphase nucleus by visualization of specific target DNAs with radioactive and non-radioactive in situ hybridization techniques: diagnosis of trisomy 18 with probe L1.84. Hum Genet 1986;74:346-52.

24 Zahed L, Murer-Orlando M, Vekemans $M$. In situ hybridization studies for the detection of common aneuploidies in CVS. Prenat Diagn 1992;12:483-93.

25 Bland M. An introduction to medical statistics. Oxford: Oxford University Press, 1987.

26 Ried T, Landes G, Dackowski W, Klinger K, Ward DC. Multicolor fluorescence in situ hybridization for the simMulticolor fluorescence in situ hybridization for the sim-
ultaneous detection of amnoitic fluid cells. Hum Mol Genet 1992;1:307-13.

27 Ried T, Baldini A, Rand TC, Ward DC. Simultaneous visualization of seven different DNA probes by in situ hybridization using combinatorial fluorescence and digital imaging microscopy. Proc Natl Acad Sci USA 1992;89:1388-92. 